\title{
The drought, the irrigators, and their photographs: images from the inside
}

\author{
G. Kuehne ${ }^{1,2}$ \& H. Bjornlund ${ }^{2,3}$ \\ ${ }^{1}$ CSIRO Sustainable Ecosystems, Australia \\ ${ }^{2}$ CRMA, School of Commerce, University of South Australia, Australia \\ ${ }^{3}$ University of Lethbridge, Canada
}

\begin{abstract}
This paper describes a photo-elicitation study conducted with irrigators in Australia's Murray-Darling Basin during a time of severe drought. This method was chosen because of its ability to elicit the expression of more deeply felt beliefs and values than interviews by themselves. Using visual methods combined with personal interviews, the aim of the study was to uncover the influences on irrigators' decision-making and their expectations for the future. The analysis of the interview transcripts in conjunction with the analysis of the photographs shows that irrigators have become dispirited and often no longer see a future for themselves in the industry. It was also evident that non-profit-maximising values, such as lifestyle and the prospect of family succession, are still powerful influences on irrigators' behaviour, even during a time of such severe financial distress. This study suggests that the programs and policies aimed at assisting irrigators, even during this time when financial issues could have been assumed to have been their most pressing concern, could be better designed so that they provide a more compatible match with irrigators' values and attitudes. This would potentially lead to less social, environmental and economic distress for the individuals and communities of the irrigation regions.
\end{abstract}

Keywords: decision-making, irrigators, photo-elicitation.

\section{Introduction}

Drought in Australia, while a regular and expected occurrence, is not usually expected to be as persistent and as severe as that currently being experienced in 
the study area - the South Australian Riverland. The drought has resulted in the lowest recorded inflows into the Murray-Darling river system over an extended period of time [1]. This has had a profound effect on Riverland irrigators, who have been accustomed to receiving $100 \%$ of their irrigation water allocation. However, in 2006-07, due to the low inflows, this was reduced to $60 \%$, then $32 \%$ for the following season and for 2008-09 to $18 \%$. In addition to declining water allocations, Riverland irrigators have at the same time experienced declining returns from their produce, primarily winegrapes and citrus, and a weakened property market. These unfavourable conditions have depressed the morale of the region. In the 2006-07 season $30 \%$ of grape growers were considering exiting the industry [2], however, by $2007-08$ this had risen to from $50 \%$ to $60 \%[3,4]$. Irrigators were forced to consider a range of measures for adapting to the commodity price slumps and the ongoing drought.

The aim of this research is to develop a better understanding of the influences on irrigators' decision-making under harsh and demoralising conditions - in this case a combination of severe drought and declining commodity prices. The study uses the decision of whether to sell water to the government for environmental purposes or not as the dependent variable. Research has been done on the influences on farmers' decision-making, but often without considering the context of the decision-making, and with a group of farmers coping with such trying conditions.

The measure examined in this study, the decision to sell water entitlements, is especially poignant given that there is little chance to continue operating a farming business in the semi-arid environment of the Riverland once the water has been sold.

\section{Methods}

This study uses a multi-method approach; quantitative and qualitative mail-out survey and photo-elicitation interviews. Mail-out surveys were posted to the Central Irrigation Trust irrigator mailing list on 12 November 2008 with 291 surveys returned ( $23 \%$ of those posted). The forty questions (eight qualitative) gathered information from respondents about their: 1) farming operation; 2) management response to the current water restrictions, and 3) personal information. Data were first entered into Microsoft Excel ${ }^{\mathrm{TM}}$ and then analysed by generating cross-tabulations and chi-square tests using the SPSS ${ }^{\mathrm{TM}}$ statistical package.

Irrigators who 1) returned mail-out surveys, 2) agreed to be interviewed, 3) were resident landowners, and 4) provided detailed responses to the open-ended questions of the survey, were invited to participate in the photo-elicitation interviews. All who were approached willingly agreed to be involved because they wanted to tell a story about how they were being affected by the low irrigation allocations and the low commodity prices. Digital cameras and the instructions for the photographic topics were sent to participants two weeks prior to the interviews. The ten photo-elicitation interviews were undertaken from 19 December through to 22 December 2008. The interviews were digitally recorded, 
fully transcribed, and then coded using Nvivo 8. Statements were coded if they illustrated the influences on irrigator's decision-making.

Photo-elicitation is a useful research method because it provides the respondents time to consider questions and decide which photographs to take to best reflect their perceptions or opinions rather than being confronted with questions in an interview requiring an immediate response. The photographs which are inserted into the interview setting become intermediaries in the interviewer-interviewee relationship; focussing discussion on the image rather than the interviewee and helping to overcome status differences. They can allow for reflection, prompt spontaneous interviewee comments, facilitate freerflowing exchanges between interviewer and interviewee, and encourage reflexive attention to specific and broader issues [5] as well as uncovering meanings that might not be uncovered in face-to-face interviews [6]. The use of photographs also assists in bridging the divide, and reducing potential awkwardness that can exist between the researcher and the participant - two people who are rarely likely to share the same cultural backgrounds $[6,7]$.

In addition, because the participants are responsible for choosing what to capture in the photographs they are rebalancing the power relationship between the researcher and the interviewee [8]. This shift from a "researcher-centric construction of the social world" [9, p. 17] results in a more collaborative approach where the research is done 'with' participants rather than 'on' participants.

The choice of the photo-elicitation method was validated by an interviewee's comments:

"I mean I know it's really good taking photos, you can sort of um talk about anything when you've got the photos. Yeah I'm actually thinking more about [the topic]...when I got this I wrote down things that I could take photographs of."

\section{Results and discussion}

In this section some of the results and discussion from the mail-out survey are presented, followed by quotes and discussion from the photo-elicitation interviews. These discussions are used to form a model (see Figure 1.) explaining the dominant role of succession (business continuity) in the decision to sell water to the government or not.

The qualitative and quantitative responses to the survey showed that those without an expectation of family succession have a greater interest in the sale of water because they do not require the water to develop a business to hand over to the next generation. Those who expect to have family succession are divided between, 1) whether they would sell or consider selling water and 2) having no interest in selling water.

Those unsure of family succession are strongly disinterested in selling water; however this could be expected to change when that uncertainty is resolved. Indicating a lack of optimism in the region, $60 \%$ of participants are unlikely or 


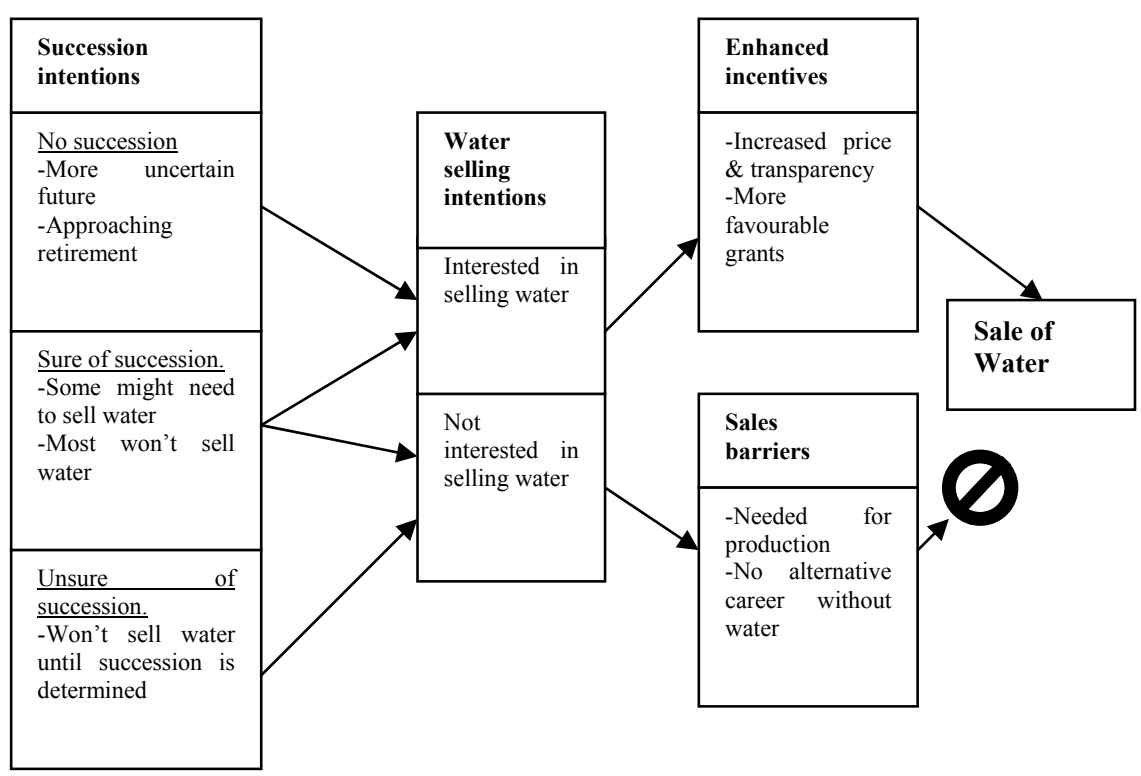

Figure 1: Influence of succession on the sale of water.

very unlikely to have family take over their farm business, $12 \%$ were unsure, and only $20 \%$ were likely or very likely to have family successors. This is half the proportion of irrigators expecting family continuity in 1998-99 [10].

Those who are certain or very certain of a long-term farming career are more unlikely to have considered selling their water. Although it may be that the farmers who have already sold their water, or who have committed themselves to selling their water at some point in the future, and those that see their sale of water as inevitable, would also anticipate a very uncertain career as a farmer.

Those farming because they can't sell their property are more likely to have considered selling their water. (Properties have sold, but at a substantial discount and although many were advertised for sale, few sales were occurring during the time of the research.)

Those who had, 1) no alternative career, or 2) liked the lifestyle, were unlikely to sell their water. Respondents who are uninterested in selling their water are not strongly influenced by the price they could receive for their water. This is likely to be because they have a productive use for their water that is of more value to them.

On the other hand some farmers are quite willing to sell especially if prices for water rose to levels higher than those currently on offer. They would also sell if access to the 'Small Block Irrigators' Exit Package' [11], the government's initiative to motivate irrigators to sell their water by providing a $\$ 150,000$ grant, became less restrictive. An indication of the seriously weakened financial state of many of the irrigators in the Riverland is their desire to access the exit package regardless of the conditions which require the sale of all their water to the 
government, and a five year embargo on their property being used for irrigated agriculture.

Those in the fifty-one to sixty years of age group are more likely to have considered selling their water. The up to fifty years of age group are equally divided on wanting to sell their water or keep it, whereas the sixty-one years and older group are less likely to want to sell their water. It may be that the oldest group want to keep their water until the time that they retire from farming at which time they intend selling their water to provide a superannuation equivalent.

For the interview analysis, participants' photographs were combined with the parts of the transcript where the photographs were discussed. Due to the limitations of this paper only illustrative examples of the photographs are provided here. Other coded parts of the transcript are also presented where they are relevant to the discussion on influences on the decision to sell water or not.

The interviewee providing Figure 2 said:

[This is]...the future ... It's what I do it for.

This interviewee's work is being done for the family. But for others the current unfavourable conditions have influenced succession intentions.

I think [my son] sees that he doesn't want to go through this, ... we're on Exceptional Circumstances drought relief. That's what we're living on....

Not everyone is defeated by the drought; some believe that the situation will eventually improve (Figure 3 ).

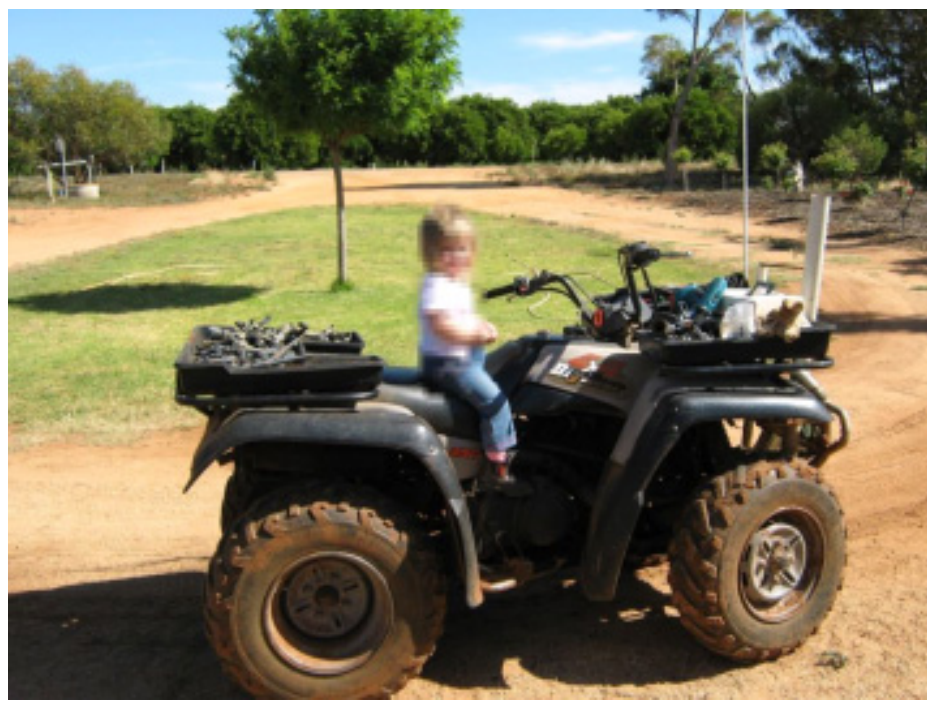

Figure 2: Family members are the focus of the future. 


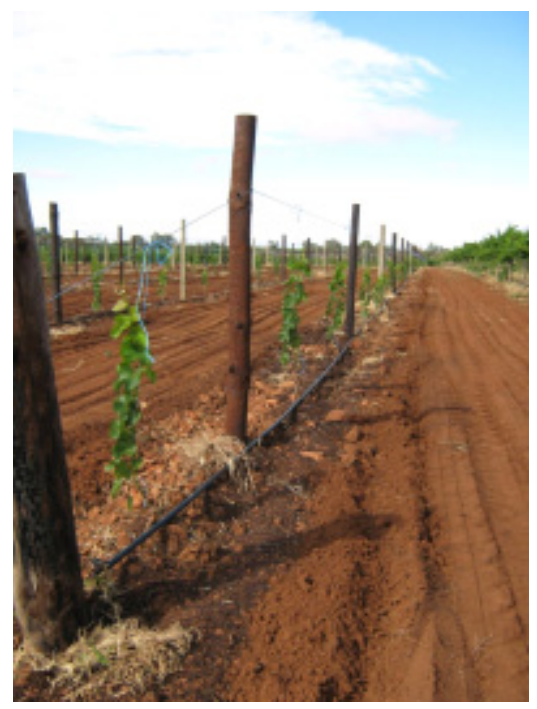

Figure 3: Optimism still exists.

There's six acres out there ......it's a bit of optimism in tough times. So how can we explain that ... Faith basically ... and a fundamental belief in oneself. ...

At the time of the interviews farming offered a much less rewarding career than it had in the past. Many reported that their children had elected to find alternative and more rewarding careers than farming. Some farmers appeared to believe that they have been successful if their children did not become farmers.

But still I don't regret it, I mean you know we had a family of six and the kids had a good upbringing and good country life and they've gone off and done better things.

The farmers seem to recognise that their children may not want to continue on with the business:

... They've seen what's happening, I mean they can see what it's done to us, you know you just struggle along.

The children of farmers who overcome the pessimism of others, and are still keen to take on the business, can be faced with difficult choices:

He's starting to realise that to put it together the amount of money he needs ... won't give him a quality of life ... wanting to be a farmer can destroy you ... you really have to then commit everything of you to make it, you don't get the financial rewards of that until it's too late in life.

Family succession as a form of inter-generational change has been interrupted by current events. 
... we were trying to buy more land and, and the plan was to just do the expansion and then to gradually do the generational change. These water restrictions have stopped the ability to do that for us and I think for much of the district so the capacity to do the generational change is just about squeezed ...

The drive to continue the farm business is strong for farmers with willing successors but it is less so for those without likely successors:

I was seriously looking at expanding and buying more vineyards because I see the opportunity there but then I think $\ldots$ in the end why would I do it, because I don't need to concern myself about the whole family succession process.

A recurring comment is that growers feel trapped into continuing as farmers by the current circumstances.

I can't see us getting out of this in the near future anyway 'cause you can't sell the property, nobody's interested in buying any more, unless you want to be trapped here you're going to take the best that's on offer and try and get out ...

Some farmers have a strong desire to remain on their blocks and in their community. The people that would like to sell their water but remain living in the area often appear to be toward the end of their working life, and have an attachment to community that spans many years.

I know people who want to stay because they've committed themselves ... They've got nowhere else to go anyway so they're really committed to staying on.

Some farmers show the effects of the drought are not just financial but also emotional. It seems that some people who have made all the 'right' decisions are now the ones who are caught up in this crisis (Figure 4 shows the place referred to in the second of the following quotes).

[W] came up here for semi-retirement. I know it's hard but it develops character, perseverance and endurance, it really does. Within two years we'd worked out that we'd made a bloody great mistake buying it, it was the worst thing we ever did.

That is my least favourite place, it's a fallen gum tree and it's fallen on the orange trees that are dead and it's impossible. ... it's been sitting there for two years.

For many the present situation invokes feeling of powerlessness, being trapped, of stress and of hard work for little reward. The business environment has changed substantially, quickly and unexpectedly, so that someone who was once making a good living can now be faced with a business that is rapidly becoming unviable. 


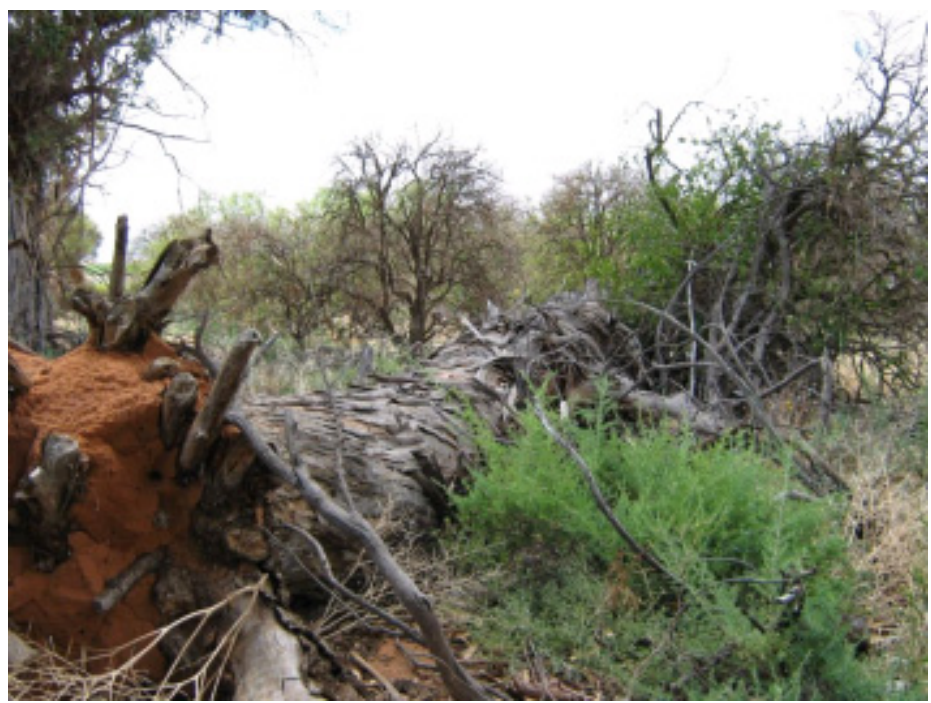

Figure 4: $\quad$ Powerlessness is overwhelming for some.

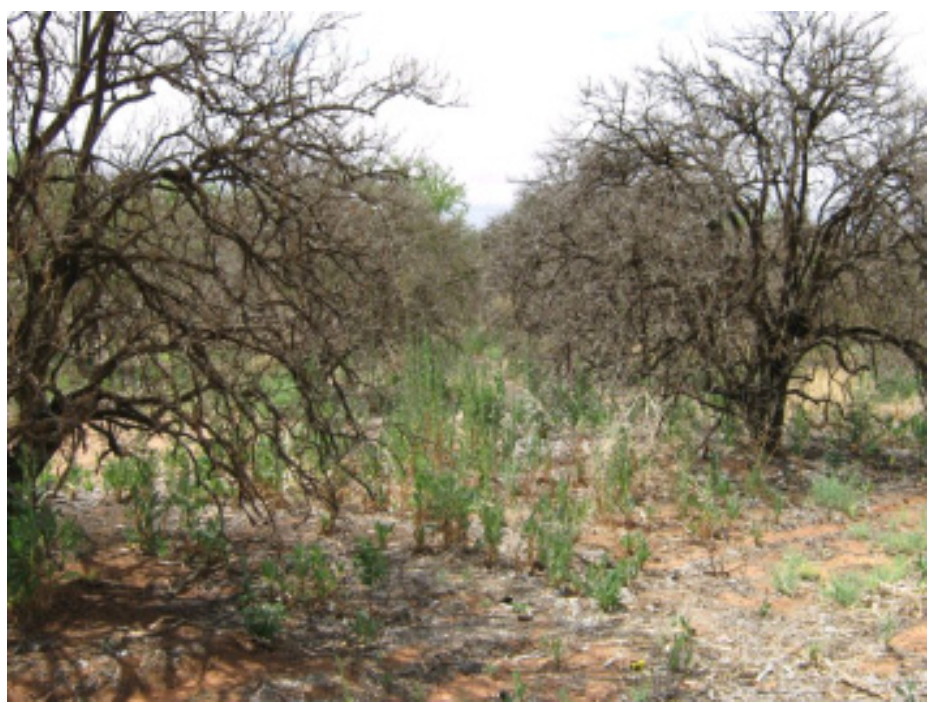

Figure 5: Hard decisions need to be made.

...it was a hard decision to make to - I mean you had to make it, everyone was saying yeah you've got to stop watering something... I've had years of good fruit on these trees...they're old. ... Old as me-fifty-five years.

This grower had serious difficulties in making the decision to let the trees die (see Figure 5) because of his long term relationship with them; it almost appeared as if he considered them as a part of his family and his life. The 
decisions he makes need to be made in light of the responsibility and the stewardship that he feels for these living things.

Generational change is likely to become a difficult issue for many of the horticultural and viticultural businesses of the Riverland.

I'm forty-eight and now that's really scary going to meetings and all you see are old men, I see that the exit strategy is a perfect situation where if you can allow many of these people to retire from the industry ...

Succession plans have needed to be adjusted, meaning that for many in the Riverland, trouble-free generational change has become less likely.

When you take the water off a property ... they're not just buying the water they're buying the whole business ... And for a lot of guys around here it's their superannuation ... It's their whole life savings. ... Most growers around my age, I'm fiftythree, a lot of these guys are looking to retire ... the idea was of course that you build your property up and if you're wealthy enough to do that you'd hand it on to a son or whatever, or if not you'd sell it to a neighbour.

Retirement expectations have now changed for many in the Riverland as the value of their property has reduced:

It was our superannuation ... we had two million dollars worth of property. We were going to somehow pass it over to our son. This was the option five years ago.

Water is valued by these growers because it allows an annual production of fruit, vegetables, nuts or wine grapes. But it is also water that determines the value of their property. The ability of irrigators to retire comfortably after a lifetime of hard work is made possible by the value contained in their property. Some intended that this retirement took place on their property, so that they remained living in the same house, but for others this was not so important.

\section{Conclusions}

This research has sought to elicit details about non-profit decision drivers during a period of extreme stress, hardship and uncertainty in the Riverland of South Australia. Responding to low commodity prices, an on-going drought and the Australian Government's moves to recover water from irrigators to be returned to the environment, many irrigators were considering the difficult decision of whether to sell water to the government or not. Because of the importance of water this is also a decision whether to leave farming or not. Many of the farmers who participated in this research are some years away from retirement, and have little prospect of finding fulfilling alternative employment should they exit the industry. Many are uncertain about plans for family succession or, if a family member plans to continue on in the business, whether the future rewards of farming will be worth the effort for them. 
When considering the sale of water we found a confluence of non-profit and profit maximizing values influencing farmers' decisions. They include 1) whether the farmer wishes to continue farming in the future, 2) years they have left until retirement, 3) whether family succession has been arranged, 4) their future employability, 5) the eligibility criteria of the exit grant package, and 6) the price on offer for water.

Financial considerations do have a strong relationship with a decision to sell water, but non-profit decision drivers still continue to be important influences on farmers even during times of severe financial stress.

\section{Acknowledgements}

This research was funded by Rural Industries Research and Development Corporation, Dept. of Sustainability and Environment, Dept. of Primary Industries and Resources of SA and University of South Australia.

\section{References}

[1] Murray-Darling Basin Authority, River Murray System Drought Update. 2009, Murray-Darling Basin Authority: Canberra. p. 1-7.

[2] Chambers, M., A survey of wine grape growing farms in the Murray Valley and Barossa regions, 2006-07, in ABARE research report 08.11. 2008, Australian Government Department of Agriculture, Fisheries and Forestry: Canberra.

[3] Cummins, E., SA growers prepare to quit struggling industry. Grapegrowers and Vignerons, 2008. October: p. 4-5.

[4] Riverland Drought Taskforce, Riverland drought taskforce regional submission Productivity Commission's Government Drought Support Inquiry 2008: p. 1-13.

[5] Parker, L. Photo-elicitation: an ethno-historical accounting and management research prospect. In 4th International Critical Management Studies. 2005. University of Cambridge, Cambridge, UK.

[6] Clark-Ibanez, M., Framing the social world with photo-elicitation interviews. American Behavioral Scientist 2004. 47(12): p. 1507-1527.

[7] Harper, D., Talking about pictures: a case for photo elicitation. Visual Studies, 2002. 17(1): p. 13-26.

[8] Kolb, B., Involving, sharing, analysing-potential of the participatory photo interview. Qualitative Social Research, 2008. 9(3).

[9] Prosser, J. and Loxley, A., Introducing Visual Methods, in ESRC National Centre for Research Methods Review Paper. 2008, National Centre for Research Methods. p. 65.

[10] Bjornlund, H., Markets for water allocations: Outcomes and impacts, in Water Down Under. 2008: Adelaide.

[11] Prime Minister of Australia. New exit grant package to assist small-scale irrigators. 2008 [cited 200927 January]; Available from: http://www.pm.gov.au/media/Release/2008/media_release_0487.cfm. 